This item was submitted to Loughborough's Research Repository by the author.

Items in Figshare are protected by copyright, with all rights reserved, unless otherwise indicated.

\title{
Identity work - organising the self, organising music
}

PLEASE CITE THE PUBLISHED VERSION

PUBLISHER

(c) Cambridge University Press

VERSION

AM (Accepted Manuscript)

\section{PUBLISHER STATEMENT}

This work is made available according to the conditions of the Creative Commons Attribution-NonCommercialNoDerivatives 4.0 International (CC BY-NC-ND 4.0) licence. Full details of this licence are available at: https://creativecommons.org/licenses/by-nc-nd/4.0/

\section{LICENCE}

CC BY-NC-ND 4.0

\section{REPOSITORY RECORD}

Coupland, Christine. 2019. "Identity Work - Organising the Self, Organising Music". figshare. https://hdl.handle.net/2134/16700. 


\author{
Christine Coupland \\ Identity work - organising the self, organising music
}

Music constructs our sense of identity through the direct experiences it offers to the body, time and sociability, experiences which enable us to place ourselves in imaginative cultural narratives...but what makes music special for identity - is that it defines space without boundaries (a game without frontiers). (Frith, 1996: 124-125)

How do I know who I am until I see what I say? (Coupland, 2012)

People who have an interest in identity work hold certain assumptions about the world. These include a belief that we craft ourselves, moment to moment, in interaction with others and our environments. An interaction which comprises embodied, emotional and articulated practices. This is not to suggest that we can 'be' anything but it does suggest a belief in our active capacity to produce a plausible self within the confines of what is possible. I will unpick that a little. If I were to claim to be a brain surgeon while operating a supermarket checkout I may not be believed. However, if I were to put on a white coat and walk the corridors of a hospital making this claim there would be a greater tendency to believe me. Thus, how we behave in particular contexts, what we say, and what we do, all say something about ourselves - our identities. We may have many conscious and subconscious motivators to produce a plausible self through identity work, but the desirable outcome remains the same - for people to believe you - for your identity work to produce a plausible self.

Why would organisation theorists be interested in this activity? Good question. Of course many of them are not, just a select number of people who have made a connection between how we organise ourselves and what impact that has on what we do. From very early studies, carried out by the Chicago School of sociologists, a study of identity work began to show how people craft their selves in talk (Snow and Anderson, 1987). Scholars have considered how an interest in identity allows a study of time, culture, language and history. In contemporary times identities appear as, never unified, increasingly fragmented and fractured- never singular but multiply constructed across different, often intersecting and antagonistic, discourses, practices and positions. Within this apparently conflicting collection of assembled selves, identities are constructed within, not outside, representation and discourse (Hall, 1996: 4). And a study of their use, in both the mundane and spectacular occasion, enables us to ask questions around the resources of history, language and culture about who we can be.

More recently, scholars have been interested in how we do this identity work (Beech, 2008; Watson, 2008) and how scholars look at (or for it) in research (Alvesson et al, 2008). A number of academics have made some explicit links between language and identities, drawing on core disciplines of psychology, social psychology, sociology and anthropology and applying them to a study of organising (Ybema et al, 2009). 'Identity is not seen as a thing that we are, the property of an individual, but as something we do. It is a practical accomplishment, achieved and maintained through the detail of language use' (Widdicombe and Wooffitt, 1995: 133). Organisation theorists are interested in what we do because they would like to be able to a) 
understand it more clearly, b) predict it more accurately and c) control it more precisely. (Please note that $\mathrm{c}$ ) is optional for some organisation theorists.)

There are several debates that surface as people attempt to study identity work. The most important one resonates around to what extent we are free to produce ourselves. That is, how much agency do we have and what are the institutional controls that prevent us from having complete agency? Institutions in this instance can include real or imagined systems of meaning around gender, class, education, etc. that offer limits to what we can be. They provide conditions of possibility within which we are able to craft ourselves. Other debates circulate around to what extent it is possible for other people to regulate or control your identity. And there are further debates around whether any agency is an illusion, whether we craft ourselves from ways of being that are largely pre-determined because of powerful (hegemonic) discourses around who we should be.

Before we move on to look at how this approach might be useful in order to understand practices of organising music it is, perhaps, useful to look at examples from studies of understanding identity work practices more generally in organisations.

It is not just an individual who engages in identity work, whole organisations attempt to do it too. Corporate identity claims are made up of images and words that legitimate one, or a few, preferred versions above other possible ones. They are visible in artefacts (buildings, web sites, mission statements, corporate literature) as well as in organisationally espoused values. However, in a similar way to me making a claim to be a brain surgeon while scanning the frozen peas, they are made in a context of alternative meanings being available, thus they can be contested by the receiving audience. In an earlier, published' paper I demonstrated this by looking at a number of oil producers' web pages to see how they claimed to be corporately socially responsible on their corporate web sites. It was at a time when there had been recent, damaging, oil spillage in Nigeria and the world had started to take notice of what the large corporations were doing in less developed countries. So, the context was one in which there was an alternative argument that they were not very 'responsible' at all. A great deal of identity work was done by the oil producers to counter this alternative viewpoint of the kind of organisations they were. The following extract is an example of identity work carried out on a web site in the above described context where the corporate view is crafted for an outside audience.

"To conduct business as responsible, corporate members of society, to observe the laws of the countries in which they operate, to express support for fundamental human rights in line with the legitimate role of business and to give proper regard to health, safety and the environment consistent with their commitment to contribute to sustainable development."

The competing ideologies of business and the environment can be seen to be woven into the text in this extract. It was ostensibly about the company's responsibility to society. However, a close exploration of the account makes visible how business concerns are positioned over societal concerns throughout the argument. In the first instance, the descriptor 'corporate members of society' appears to suggest that the organisation's first concern was a corporate one. Secondly, 'to observe the laws of 
the country in which they operate' places responsibility for perceived unethical behaviour outside the company - but within the law and therefore being in accordance with the socially operable judgements pertinent to the local context of the behaviour. In addition, the term 'to express support for fundamental human rights' is interesting; it is unlikely that a company would argue to not support human rights. The qualifier to the statement 'in line with the legitimate role of business' positions the claim to support fundamental human rights as operable from within a business context.

Thus, the corporate argument can be seen to be slipping between business and environmental issues, selling one in terms of the other, mitigated through a claimed adherence to law. The circle of argument is retained through the act of attending to these oppositional forces, but some close reading of the text illustrates how the environment is subsumed under the more dominant rhetoric of the business case (Coupland, 2005).

On a more everyday level, we routinely and mundanely craft ourselves for public exposure. We not only use the artefacts around us to promote our preferred view; what we wear, the car we drive, where we choose to live and work, they all present a picture of our selves. We may feel that we exercise some choice around some of these things, that they are within our control, at least for some of the time. But, in addition, the way we talk about ourselves, while doing our everyday interactions, is also part of our identity work and is more subtle, I would argue. Sometimes we are careful about how we construct what we say, but most of the time our concern with getting things said in a convincing way means we produce ourselves as a sideproduct of doing something else. This is the identity work that interests organisation scholars as we argue that everyone brings to view how they are organised through language practices of legitimation, blame, justification and accountability.

So, to move our focus specifically to musicians' identity work; research suggests that there are patterns of ways of speaking that creative people draw on when being asked about their work. Recall that the assumption is, what we say says something about us - even if we are talking about something as mundane as the weather? In an earlier study of musicians' talk we found that, along with descriptions of events, or festivals, etc., threaded through these stories are accounts, of the self as a legitimate player, as a rightful member of a community. These patterns appear as the speaker engages in identity work around, the creative self-project, the creative act and the organised creative. As organisation theorists we are interested in how each of these themes are constructed and performed in musicians' talk (Coupland et al, 2013).

There are many ways that this identity work is made visible to an intended (and sometimes unintended) audience. How musicians dress, how they behave (who they please and who they offend) and how and what they perform all carry out forms of identity work. For the purposes of this chapter, in the interests of brevity, we are focusing on how people speak about themselves, how identities are worked up and deployed in talk. Some examples of this include, how, when asked to describe their involvement in a particular creative project, they pre-empt their account with descriptions of venues that they have played at. It may be that their significance is known in the main to the cognoscente, but there is lightly coded set of messages around having played in certain places (big venues, elite venues, cool venues, 
supporting major artists etc.). These markers are a pattern that you can see/hear in everyone's talk. It is so mundane that we miss it most of the time, but it is important as it is identity work that is going on between two people as each finds out more about who the other person is. They are working up a warrant to speak. Here is a typical example exchange below:

Musician 1 I worked with Dog City, (a record label, pseudonym) the singer Joanna Newsome (pseudonym) kind of big cult appeal I have opened for her a few times, are you familiar with her music?

Interviewer No is she good

Musician 1 American singer yes she is good

(Adapted from Coupland et al, 2013)

There is a lot that can be said from this tiny extract of talk, so I will point out just a few ways in which identity is working here. First, consider how talking about working with a record label positions the musician as one of credibility. This credibility is enhanced by drawing on an association with a big name - notice, however, when the speaker's awareness that the interviewer is not one of the musician's peers is made evident as he checks if the interviewer is familiar with the singer's music. The interviewer joins in here with the musician's identity work by asking the expected question 'Is she good?' At the risk of stating the obvious, you would not mention working with someone who is particularly bad at singing - nor would you mention working with a relatively unknown artist. So, the interviewer joins in the game, or work, of constructing a credible identity which legitimates and justifies his involvement with a particular project. A final observation; the musician gives a more detailed response to the interviewer's question than just 'yes' for the final comment. He adds detail which may enhance/strengthen the singer's credibility for a nonmusician interviewer.

Other markers of significance emerged during the same study, which were quite subtle. These were worked up as 'evidence' of belonging in an authentic way within an understood hierarchy of what it is to be a professional musician. I have reproduced below an extract in which the musician talks about what is important when composing music. We can make the argument that, (much like oil producing companies having to work up plausible socially responsible identities), an authentic musician identity may be tainted in some way by association with 'mainstream' popularity. Talking about emotion is key here as it appears to function to deflect a possibility that writing for a mainstream audience in a strategic way would not be authentic.

Musician 2 for me the most important thing is to get an emotion across through a song, if that ends up, if someone in the mainstream listener likes that song then that is fine because I know that I was not thinking about that, I was thinking about my personal connection with the emotions throughout the song.

(Adapted from Coupland et al (2013)) 
So, it could be argued that some of our identity work involves crafting what we are not, or what we do not do, in our creative endeavours. Thus, musicians' concerns, as creative people, appear to revolve around authenticity and a belonging to a community of other people of authenticity, however diverse that community may appear to be. We can extrapolate beyond these extracts here and ask the 'So what?' question. Why would an organisation studies scholar, or someone who is interested in how music and musicians may be organised find this kind of analysis useful? There are many possible responses to that question. First, by looking at patterns of legitimate belonging we can work out who the community includes (and who it does not). We can work out aspirational belonging with a view towards future collaborative work. Second, how a creative person organises their selves (from a range of multiple, possible, options), for work, or interactions about work, shows alternative ways to organize - some that work well and others less well. Finally, we can consider, by looking closely at identity work in language, how this self-organising impacts upon the creative act - or to look at this another way, how does the creative act articulate or shape who we are?

Three themes of understanding- the creative self-project, the creative act and the organised creative- gained from analysis of identity work, will be illustrated through some analysis of Marco's story in the remainder of the chapter. The purpose of an illustrative analysis of Marco's story enables a speculation on how these ideas may relate to practices of organising music more generally.

Any analyst who is interested in identity work will consider - what came first? What I mean by this is, how do people begin the story of 'them'? Drawing on the story of Marco taken from this volume (the reader will have a collection of musicians' stories as part of the book) I will demonstrate how someone, by looking at identity work, can see how our assembled selves are built into fragile coherence from the discourses available in cultural and historical contexts generally and deployed specifically in interaction.

In this instance the individualistic title 'Marco's story' immediately moves to the collective 'The Band'. Analysts can make much of how we position ourselves as separate from or closely aligned with collectives or others. Organisers of people need to understand how we see our 'selves' as close to, or distanced from, others and who those others might be, as it will impact on potentials for organising. So, we are individuals who speak as individuals when asked about ourselves - or our storybut we quite quickly describe ourselves as a part of a collective for reasons sometimes unknown but often to do the discursive business of legitimation, blame, justification and accountability. Thus, in the first section of the story, entitled, The Band, the description provided by the crafter of the story draws on some of the legitimating techniques, (venues played, bands supported etc.), described in the earlier study of musicians' talk. The 'Background' section enables the story teller to dislocate temporally. What this does as far as identity scholars are concerned is to retrospectively make sense of who we are today. It is a story of legitimation - even, for example, if you are telling a tale of crime and a spell in prison, you are an (arguably) moral person who now knows (or is) better. Thus, retrospective telling allows us to re-story the past to create a version of us for today. Marco (or his biographer) selects this collection of descriptions of the many possible:

The Band...had previously been done over by their record label 
(the two friends spent the following year just listening to music)

The Band is his first proper attempt at being in a professional band

(before this he had been just writing songs on his own)

Marco recalls a point when the power shifted and we became one of those bands that other bands were asking to do that (supporting other bands)

(Building friendships with other bands is just what you do in order to become established)

Marco is also the band's manager and feels that networks are vital for learning how the music industry works

The above are extracts from the background story. What appears in the text is a seesaw effect of minimizing what went on before followed by the 'real' effect of what is happening now. The pattern works to set up action following inaction, or organised following not- or dis-organised. This operates as a description of what has happened (a history) made up from selected pieces of relevant information. The sub-text, or identity work, that seems to thread through this is one of minimising being strategic. This is important to know if, for example, you were a festival organiser and you interviewed Marco for his suitability to head up a big festival involving lots of planning and co-ordination. At first glance you might imagine that Marco likes to drift along with the occasional realization of arriving somewhere else almost by accident. However, as an identity scholar I would argue instead that he is 'doing' his creative identity as a musician over and above an organised or strategic identity that may, in perception, dissolve or challenge his authenticity as an artist. This is not to suggest that Marco consciously adopts one position over another in talk - rather, he has subconscious concerns around authenticity and so in talk he downplays his own agency with regard to being active in organising the band. Consider his explanation of becoming a headliner rather than a supporting act, 'the power shifted', where he places agency elsewhere - nothing to do with him and his endeavours - or at least he writes his own efforts out of the story. Note how this is contradicted further down the text, 'as the band's manager he feels that networks are vital...'. With an element of identity work (self-labels as the band manager) he gives himself warrant (justification) to be strategic, knowledgeable, about what is required, instrumental and highly organised. I would suggest he would make an ideal festival organiser.

As we have paid some attention to the beginning of Marco's story it may be interesting to look at the end - so far, entitled 'The future...'

Most of this part of Marco's story is structured around his and the band's attitude towards signing to a label. It is well known that signing to a record label has both risks and benefits attached. Most predictably, it is a signal of esteem, belonging to the community legitimized by one of the gatekeeper groups. Less well known, perhaps outside the musician community, are the risks to artistic integrity, loss of autonomy and reputation by association with an inappropriate label. Thus, tensions are evident as this description is given by the storyteller. With regard to identity work by Marco he constructs 'bothered but not bothered' in the following extract:

'We just have to keep working as if we are never going to get a deal, that is really attractive to labels, it sounds terrible but they just want to waltz in there 
and not have to do any work. If we can show them that we are a selfsustaining band that work hard in their own right, then it is much more attractive than it is to sign a band that don't know what they are doing and that they have to work really hard to get them on the right tracks.'

What I mean by 'bothered but not bothered' here is that he constructs a hard-working identity for the band (they do this anyway)- a record label would not affect this. The record label members are then positioned as wanting to sign a band and not do any work. Thus, a not-so-subtle moral positioning is carried out. It is evident that record labels hold the power of recognition (legitimation) for bands but it is possible to undermine their right to all this power. The creative musician is after all the producer of the artefact that the record label wants to sell, without their labour the record labels would cease to exist. The gatekeeper identity is thus challenged as necessary but perhaps peripheral to their endeavours. The tentative relationships are constructed in the extracts below:

When talking about the next move 'signing up to an independent label' they

'are talking to a couple'

'they have one label who are really keen and would sign us tomorrow'

They are talking to another label that has

'shown a little interest and I would stress 'a little”

But the quality of the label is relevant

'we would only appreciate the view of a label that had produced really good artists'

'they've got good taste or taste along the lines of ours'

Though

'we might find no-one is interested'

However

'there is no point jumping the gun when there may be a much more influential label that wants to work with us'

There are many things occurring in these extracts that are identifiable as identity work. One of the key things is how the individual (as a member of a band) constructs his/their relationship with a larger collective - one that has the potential to organise their work for larger audiences. This relationship is constructed as tentative, 'talking to' suggests a negotiated process - not too committed but showing an interest (in both directions). This enables a speaker to demonstrate legitimacy (through the labels' interest) but agency (it is the band's choice whether the label would be right for them). These extracts, taken from a series of 'turns' in talk, are reproduced in the original order, and the final two comments appear to summarise tensions in managing this process. The identity work above, despite identifying a number of labels who are showing 'interest', suggests that it may come to nothing. Marco (and 
the band) have to make sure they have the label with the most appropriate level of influence before they decide to sign up.

What is being demonstrated here is a nuanced understanding of what is valuable. Members of bands may well feel that they would like the legitimacy of being signed to a record label but creative artists will have a process of estimating the costs (artistic, emotional, social, cultural) attached to signing with a label that does not have 'good taste'. Thus, on a micro scale, in some fine detail, we can see selforganising occurring as the individual or group aligns with, or rejects, other groups or collectives, despite their apparent power to increase their exposure to a public. It is not so much that there is a conflict or tension emerging as being organised and being creative are conjoined, it is that, for an independent, creative, worker artistic authenticity cannot be compromised through association with inappropriate groups however powerful they may be.

\section{Summary}

For creative people, as with any other people, there are patterns of ways of speaking that people draw on when being asked about their work. In these patterns there are also tensions around how/who not to be; identity work takes place as speakers negotiate these tensions in their talk. We can imagine for creative workers they may include authentic rather than inauthentic, artistic rather than material, creative rather than productive, niche rather than popular. Managing these tensions through identity work in talk can seem quite straightforward and predictable, until we encounter the logics of business. In a similar way to the example given from oil producers earlier in the chapter who told their business story as an overarching logic that subsumed their corporate, socially responsible organisation story, it seems that one set of logics has to dominate - although there may be eruptions from other logics from time to time.

For the creative worker the dominant logic appears to be artistic authenticity. For music and musical events to be organised this has to remain the dominant logic, however, this does not preclude some creative tension with other logics, of organising, for example, without which the festivals could not take place. The purpose here is not to celebrate 'authentic' as something that can be finally achieved, but rather to examine how musicians construct and manage their perceptions of authentic identities. A further purpose is also to demonstrate how an exploration of authenticity-based identity work serves as a meaningful addition to studies of these artists' identities.

As we assume that what we say - the words that we use- says something about us, threaded through stories of events or festivals are accounts of the self as a legitimate player, as a rightful member of a community. These patterns appear as the speaker engages in identity work around the creative self-project, the creative act and the organised creative. As organisation theorists we are interested in how each of these themes are constructed and performed in musicians' talk illustrating promising practices of adaptation in creative work. 
Alvesson, M., Ashcraft, K.L. and Thomas, R. (2008) Identity matters: Reflections on the construction of identity scholarship in Organization studies. Organization, 15(5), $51-74$.

Beech, N. (2008) On the nature of dialogic identity work. Organization, 15(1), 51-74.

Coupland, C. (2005) Corporate Social Responsibility as Argument on the Web. Journal of Business Ethics, 62, 355-366.

Coupland, C., Gilmour, C. and Beech, N. (2013) Composing the self: Creative identity work. Paper presented to the British Academy of Management Conference, Liverpool.

Frith, S. (1996). Music and identity. In: S. Hall and P. du Gay(Eds.). Questions of cultural studies (pp.108-117). London: Sage.

Hall, S. (1996). Who needs 'identity'? In S. Hall and P. du Gay, (Eds.). Questions of cultural identity (pp. 1-17). London: Sage.

Snow, D.A. and Anderson, L (1987) Identity work among the homeless: The verbal construction and avowal of personal identities. American Journal of Sociology, 92(6), 1336-1371.

Watson, T.J. (2008) Managing identity: Identity work: Personal predicaments, structural circumstances, Organization, 15(1), 121-143.

Widdicombe, S. and Wooffitt, R. (1995) The language of youth subcultures: Social identity in action. New York: Harvester Wheatsheaf.

Ybema S, Keenoy K, Oswick C, Beverungen A, Ellis N and Sabelis I (2009) Articulating identities, Human Relations, 62(3), 299-322. 